\title{
La transformación del espacio urbano de Talavera de la Reina en el siglo XVI
}

\author{
CÉSAR PACHECO JimÉNEZ \\ (y la colaboración de INÉs VALVERDE AZULA)
}

\section{EL ESPACIO URBANO EN UN PERIOODO DE TRANSICIÓN. LA CIUDAD CASTELLANA A FINALES DEL SIGLO XV Y PRINCIPIOS DEL XVI}

Resulta complicado fundir en una síntesis toda una serie de elementos que componen al amplio capítulo del urbanismo en un período concreto de la historia del hecho urbano en Castilla. La gran cantidad de aspectos que podrán analizarse como ha demostrado el profesor Ladero Quesada ${ }^{1}$ nos obliga a elegir con cuidado aquellos que nos sirvan para enfocar más adecuadamente la transíormación del espacio urbano. Y esta mutación entendida y contextualizada en una etapa de singular trascendencia para las ciudades y villas: la transición del medievo a la Edad Moderna.

En España corresponde precisamente a un intento de unificación política y religiosa que se da bajo los Reyes Católicos. Algunos cambios llevados a cabo en la administración y en el campo político de los concejos son elocuentes. Los monarcas, en su afán de controlar todos los ámbitos menores de poder, van a colocar en las ciudades más importantes un representante del poder real investido de atribuciones judiciales y políticas muy amplias, los corregidores ${ }^{2}$. Esta institución se da desde el siglo XIV ${ }^{3}$, pero es a partir de este período cuando mayor auge alcanza, tanto en villas de realengo como en las de señorío eclesiástico o nobiliario. Por lo demás el poder y gobierno de las villas y lugares seguía en manos de los

\footnotetext{
1 M.F. LADERO QUESADA: «Consideraciones metodológicas sobre el estudio de los núcleos urbanos en la Castilla bajomedieval: Notas para un modelo teórico de análisis". Espacio, Tiempo y Forma, serie III tomo 4 (1991), págs. 353-366.

2 Angeles HiJANo PÉREZ: El pequeño poder. El municipio en la corona de Castilla siglos xV al XIX. Madrid, 1992, pág. 107 y ss.

3 Joseph PÉrez: La España de los Reyes Católicos. Madrid, 1986, pág. 39.
} 
regidores, cargo que solían ocupar miembros de las oligarquías locales, tanto nobles, caballeros como hidalgos, así como otros oficios importantes del municipio ${ }^{4}$.

Las Cortes de Toledo (1480) van a marcar un hito en este proceso de reorganización del Estado. En ellas se aprueban medidas que afectarían la gestión del espacio urbano. En este campo el mandato de construir en todas las poblaciones casas-ayuntamiento ${ }^{5}$ para la buena marcha de los concejos suponía una diposición orgánica para regular la vida urbana de manera más eficaz. Pero además la visita de diferentes veedores, cuya misión era la de visitar todos los años las provincias para informar entre otras muchas cosas del estado de puentes, calzadas, etc. ${ }^{6}$. Junto a esto hay que entender igualmente, el gran avance que experimenta en esta etapa la gestión administrativa de los cuerpos del Estado.

Se desprende pues una cierta preocupación de la monarquía por mantener atendidas las peticiones y solicitudes de los concejos, siempre vislumbrando un propósito político por el cual los reyes se «aliaban» con el pueblo y la baja nobleza frente a los posibles ataques de los grandes nobles que podian hacer peligrar la estabilidad de la Corona.

Este factor influye en la mejora de las villas en esta época; se da un gran salto en la ciudad al pasar de una etapa bajomedieval con marcados elementos arcaicos en cuanto a su morfología, a otra con unas concepciones innovadoras en materia de urbanismo. Los teóricos del siglo XVI van a tomar dos posturas ante las viejas urbes medievales según Fernando Marias: una práctica, que adecuaba la ciudad al nuevo plan de necesidades públicas pero sin destruir el trazado urbano preexistente. La otra opción estribaba en reestructurar y remodelar las viejas ciudades ${ }^{7}$. Lógicamente muy pocos entes urbanos fueron remodelados en su totalidad. Lo que más se dio fue una adaptación de nuevas construcciones y creaciones del espacio público (calles más anchas, plazas abiertas, fuentes, alcantarillado, pavímentación, etc.) al armazón medieval. Los

\footnotetext{
4 Julio Valdeón Baruque: "Las oligarquias urbanas". Concejos y ciudades la Edad Media Hispánica. Il Congreso de Estudios Medievales de la Fundación SánChez AlBornoz. Madrid, 1990, págs. 507-521. HiJANo Pérez, op. cit., pág. 51.

5 José PAstor Gómez: "Las Cortes de Toledo de 1480». Toletum, 1 (1955), pág. 68. En el caso de Talavera se registra la existencia de casas consistoriales ya en 1446.

6 Ibidem, pág. 69. Ver también Luis SuÁrez Fernandez: La España de los Reyes Católicos (1474-1516) en Historia de España de R. Menendez PIDAL, t. XVII, vol. I. Madrid, 1989, pág. 368.

7 Fernando MARIAS: La arquitectura del Renacimiento en Toledo (1541-1631), t. I. Toledo, 1983, pág. 128.
} 
pequeños municipios no podían sostener económicamente grandes obras que permitiesen un cambio radical del entramado, así como tampoco los diversos intereses de las oligarquías urbanas, verdaderos propietarios de la mayoría de los inmuebles y solares del centro de las ciudades, no siempre permitían la enajenación de esos bienes en favor del interés de la comunidad.

Muchas ciudades españolas experimentan en las últimas décadas del siglo XV y principios del XVI una expansión debido al progresivo aumento demográfico y a unas mejores condiciones económicas ${ }^{8}$. Se pone en marcha un proceso que incrementa la actividad constructora, los replanteamientos de las ciudades y villas, la terminación de grandes edificios religiosos - algunas catedrales góticas-; las rectificaciones de salientes, agrandamientos de callejuelas, apertura de plazas, mejora del estado higiénico, la limpieza de las calles, los empedrados de las vías más intraurbanas. Todo ello en pos de conseguir un más saludable y habitable ámbito urbano para el desenvolvimiento de la vida social, política, religiosa y económica de sus habitantes. Se aspira a potenciar un sentido de urbanidad propio de la cultura que se define en una ciudad y que no se da en el medio rural, como se vislumbra en la obra de La Celestina por ejemplo ${ }^{9}$. El ideal es además una ciudad menos concentrada que la medieval ${ }^{10}$.

Este fenómeno se constata en diferentes estudios sobre ciudades como Toledo ${ }^{11}$, Oviedo ${ }^{12}$, Zamora ${ }^{13}$, Sevilla ${ }^{14}$ o Valladolid ${ }^{15}$ por citar algunas. Asistimos a una dinámica por la cual se pretende dedicar más terrenos de huertos y solares, hasta entonces libres de edificios, para la construcción. Ello se debía en algunos casos al imperativo de la falta de espacio urbano que tenían las villas con murallas medievales, que constreñían al casco obligando, en ocasiones, a intentar el derribo de las cercas para

\footnotetext{
Antonio García y BeLlido et al.: Resumen histórico del urbanismo en España. Madrid, 1987. José María Maravall: El mundo social de "La Celestina». Madrid, 1986, págs. 71-78.

10 Antonio Bonet CoRrea: El urbanismo en España e Hispanoamérica. Madrid, 1991, pág. 40. Fernando MARIAS, op. cit.

12 Margarita CuARTAS RIVERO: «La forma urbana de Oviedo en el primer tercio del siglo XVI». La ciudad hispánica durante los siglos XIII al XVI. Madrid, 1985, páginas 233-247.

13 M. FeRnANDo Ladero QueSADA: "La remodelación del espacio urbano de Zamora en las postrimerfas de la Edad Media (1480-1520)". Espacio, Tiempo y Forma, Serie III tomo 2(1989),

14 Antonio Collantes de Terán: Sevilla en la Baja Edad Media. Sevilla, 1977.

15 Luis A. Ribor Garcia et al.: Valladolid, corazón del Mundo Hispánico. Siglo XVl. Historia de Valladolid, tomo III. Valladolid, 1981. Y BARTOLOMÉ BENNASAR: Valladolid en el siglo XVI. Valladolid, 1983.
} págs. 161-188. 
ampliar el terreno de habitación y tránsito ${ }^{16}$. Como dice Caro Baroja, en ciudades de este tipo se crece en altura y no en superficie al encontrarse limitada por las cercas y murallas ${ }^{17}$.

Pero las murallas, al ser un elemento vivo como las define Julio Valdeon ${ }^{18}$, se adaptaban a las nuevas técnicas poliorcéticas o se practicaban nuevas aberturas con la erección de nuevas puertas ${ }^{19}$. No significaba, sin embargo, que la ciudad quedará indefensa pues debía buscarse un consenso entre la función intrínseca del recinto fortificado con las necesidades del espacio público urbano.

¿Cuáles eran los elementos que caracterizaban a la ciudad medieval castellana que hacían imposible su perdurabilidad en el nuevo concepto urbanístico del siglo XVI? Fundamentalmente la existencia de un diseño de calle que obedecía a unas determinadas exigencias socioeconómicas: pisos altos, volados escalonadamente sobre la calle, con objeto de acrecentar la superficie de las viviendas; aleros muy salientes que estrechaban aún más las angostas callejuelas ${ }^{20}$.

Con este perfil, y la poca luz que se filtraba, debido a que los corredores, balcones y saledizos resaltaban en lo alto de las fachadas, cubrían en parte la angostura de las calles, sumiéndolas en un ambiete triste, húmedo y llenas de lodo ${ }^{21}$. No hay que olvidar la especial importancia que adquiere la calle como elemento del paisaje urbano medieval. Aún siendo estrechas (entre 2 y $5 \mathrm{~m}$. de anchura), salvo las grandes arterias, eran a menudo tortuosas, con pocas secciones rectilíneas, y las personas se confundían con los animales, por lo que la suciedad y las inmundicias existían por doquier. A finales del siglo $x v$ las calles más próximas a plazas y mercados, sobre todo en las que se celebran ferias, aparecen bordeadas ya de soportales ${ }^{22}$, elemento que se consolida en el siglo xvi en torno a las plazas mayores ${ }^{23}$.

16 Ibidem, pág. 20. Valladolid en 1552 solicita el derribo de la vieja cerca y la construcción de una nueva que albergue a nuevos barrios creados en las primeras décadas del siglo.

17 Julio Caro Baroja: Paisajes y ciudades. Madrid, 1986, pág. 165.

18 Julio VALDEÓN: «Reflexiones sobre las murallas urbanas de la Castilla medieval». La Ciudad y las Murallas. Madrid, 1991, pág. 81.

19 Ibidem, pág. 81. En esta centuria se construyen magníficas puertas en ciudades como Toledo, de corte renacentista, algunas mas monumentales que otras. En Talavera tenemos ejemplos de puertas abiertas en el muro principal para dar respuesta a las necesidades locales.

20 LEOPOLDO TORAES BALBás et al.: Resumen histórico del urbanismo en España. Madrid, 1987, pág. 141.

21 Ibidem, pág. 142.

22 J.A. García de Cortazar: La época medieval. Madrid, 1988, pág. 177,

23 Antonio BONET CORREA: «Los soportales en las ciudades españolas». El urbanismo en España..., pág. 77 y ss. 
Precisamente la plaza es una creación por necesidades de relaciones económicas. Cuando se establece el mercado junto a una de las puertas de la ciudad, por donde suele haber mayor tráfico o donde comienza un camino muy frecuentado, se van agregando al lugar edificios de los comerciantes y mercaderes con lo que el mercado se transforma en plaza pública por excelencia ${ }^{24}$.

Entrar en un análisis más profundo de las diversas características que en materia de urbanismo tenían las ciudades cristianas e islámicas de la España bajomedieval no es nuestro propósito en este estudio. Aún sabiendo que el caso de Talavera reúne en su evolución la impronta de ambas concepciones, nos detendremos únicamente en analizar algunas de las medidas llevadas a cabo en este campo en las primeras décadas del siglo XVI, que suponen una remodelación de ese espacio urbano público de la villa en el inicio de la Edad Moderna.

\section{TRANSFORMACIÓN DEL ESPACIO URBANO DE TALAVERA EN EL SIGLO XVI}

Sobre la red urbana de Talavera se ceñían tres recintos amurallados. El primero, de fundación musulmana reaprovechando abundante material romano anterior, data del siglo $x$; cerraba el cuerpo llamado de la «villa», y era el más antiguo. Dentro de éste y en su extremo suroriental se hallaba el Alcazar edificado bajo el reinado de Abd el Rahman III hacia $937^{25}$. Posteriormente, y ante el aumento de la población por el norte se levanta en el siglo XII otra cerca, acogiendo a los llamados en las fuentes Arrabales Mayores o Nuevos; este sector, más amplio, acogió tras la reconquista de Talavera en 1083, los efectivos militares y repobladores castellanos, francos, leoneses o gallegos. Al oeste, la parte de la urbe que había acogido a la población mozárabe talaverana durante la dominación musulmana, denominada «Arrabales Viejos", también se cercó a raiz de la reconquista, en las primeras décadas del siglo XII, cuya única puerta, la de Cuartos, está ya documentada en $1142^{26}$. (Ver plano I)

24 García dE CORTÁzAR, op. cit., pág. 177.

25 Sergio MARTINEZ LILlo: «Arquitectura militar islámica en Talavera de la Reina". Actas de las primeras jornadas de arqueología de Talavera de la Reina y sus Tierras. Toledo, 1992.

${ }_{26}$ César PACHECO JiMÉnez: El barrio de la Puerta de Cuartos: Historia social y cultural, en prensa. 



PRTHER RECTMTO ARTRALTADO. Ia "Vilia".

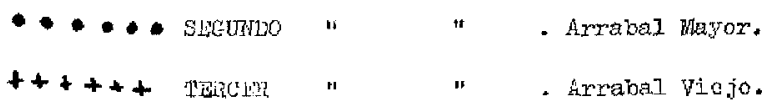

Plano 1

TALAVERA EN EL SIGLO XVI (Sobre un plano de la villa de 1830. Fuente: Servicio Geográfico del Ejército). 
Algunas de las constantes apariciones de elementos urbanos típicamente bajomedievales los tenemos en Talavera. Así por ejemplo, una de sus plazas más importantes surge extramuros del primer recinto, la actual Plaza del Reloj. Se formó muy posiblemente tras la reconquista de la villa en 1083 por la afluencia de una actividad mercantil en torno a ella. Justamente se sitúa al lado de la antigua Puerta de San Pedro, uno de los accesos principales de la villa en época musulmana, por el sector norte ${ }^{27}$.

Posteriormente queda esta plaza del Comercio o del Mercado, llamada a partir del XVI simplemente plaza pública, enclavada en el segundo recinto amurallado levantado en el siglo xII por los nuevos repobladores castellanos y francos. En torno a ella se diseña el trazado de calles que convergen en un punto, desplegando un plano de forma radial ${ }^{28}$. De éstas la mayoría tienen nombres relacionados con la actividad artesana y mercantil: Cerería, Zapatería y en su tramo final calle de Toledo (hoy San Francisco), Carnecerías o la Mesones (también denominada en esta época calle de Zamora). La otra gran vía urbana que sale hacia el oeste de esta plaza era la Corredera, lugar de juegos ecuestres y taurinos ${ }^{29}$. En esta calle pronto establecieron los mercaderes y artesanos su residencia y abrieron sus negocios y tiendas, algunas de ellas bajo los soportales de los cuales aún hay restos. Fue esta un eje importante no sólo en el aspecto económico sino también sociorreligioso, pues en esta calle se establecían los altares, capillitas, y en fin, estaciones del recorrido procesional de fiestas tan significativas como la del Corpus Christi ${ }^{30}$. No deja de ser significativo que en las fuentes del siglo XVI se denomine Calle Real a una parte de la Corredera y a su prolongación hasta la Puerta de Cuartos, atravesando los arrabales viejos para salir al camino de Extremadura. Se convertía pués en calle principal, como solían ser todas las llamadas reales al ser propiedad de la corona o del bien público. Además en estas calles solían estar edificios religiosos o residencias de nobles o hidalgos ${ }^{31}$ : en la Corredera se

27 M. Jesús SuÁrez Álvarez: La villa de Talavera y su Tierra en la Edad Media, 1369-1506. Oviedo, 1982, pág. 407. Bruno VAYSSIERE en su artículo «La Plaza Mayor dans l'urbanisme hispanique: Essai de typologie» en Forum et Plaza Mayor dans le Monde Hispanique (Paris, 1978, pág. 73) clasifica esta plaza dentro del tipo 3, de campo de feria o mercado; una vez superado su carácter de extramuro o periferia se convierte en plaza mayor: «Périphériques à l'origine, car le marchand considéré comme etranger, est suspect dans une ville entourée de remparts, elles peuvent devenir «plazas mayores" si le developpement économique et le poids politique de la cité s'accroissent".

28 Suárez Alvarez, op.cit., pág. 52.

29 Ibidem, pág. 53.

30 César PACHECO JIMÉNEZ: «La fiesta dirigida en el Antiguo Régimen: El Corpus Christi en Talavera durante los siglos XVI-XVIII». La Voz del Tajo, agosto-septiembre, 1992.

31 Balbina MARTínez CAVIRo: "La Calle Real de Toledo y el llamado plano de El Greco". Beresit, 4 (1992), págs. 169-181. 
ubicaba el convento de San Ildefonso de la Orden de San Agustín, la iglesia del Salvador, la casa de granos o Alhondiga, y varias casas de la oligarquía talaverana.

La otra plaza principal de la villa, la de Santa María o del Pan, también experimenta progresivos ensanches en el siglo $x \mathrm{v}$ y sobre todo a finales del XVI cuando adquiere su planta rectangular ${ }^{32}$. Para ello se fueron construyendo diversos caserones y palacios que iban embelleciendo el entorno y le daban la forma adecuada. Hacia 1579 se comenzaban a derribar casas en la plaza ${ }^{33}$, y el antiguo hospital de la Misericordia fundado hacia $1475^{34}$ demolía su antiguo edificio en estos mismo años para levantar uno nuevo con traza renacentista, terminado hacia $1597^{35}$. Este proceso de remodelación de la plaza principal de Talavera se consolidó a principios del siglo XVII, de tal manera que este era el aspecto que ofrecía la misma en la pluma de un autor anónimo: "La Plaça Mayor que diçen de el Pan es muy grande y mui capaz. Esta en ella la santa yglesia mayor de esta villa, cassas de ayuntamiento muy suptuosas y capaces sólo para este ministerio. El hospital de la Misericordia cuyo edificio que le adorna es muy vistoso y otras cassas principales de cavalleros adornadas y luçidas con mucho número de balcones y sirve para los juegos de cañas y fiestas de toros» 36 .

Al finalizar el siglo XVı existían ya otras tantas plazas más pequeñas y de plano irregular, pero no menos significativas. Cosme Gómez Tejada de los Reyes llega a apuntar que en muchas de ellas - hasta once- se podían correr toros "y en alguna andar gente a cavallo con rejón»; cita entre ellas la de Santa Leocadia, Santiago, San Miguel, San Salvador, San

32 Fernando Marias, op. cit., vol.IV, pág.

33 El ayuntamiento llega a un acuerdo en este año con los propietarios de las casas que obstaculizaban el proyecto de ensanche. En este se apunta: «...que las casas que son de Juan de Castrillo se tasen toda la parte que dellas fuere nesçesario para sacar la pared derecha a panleo fasta la calle que atraviesa desde las plaçuelas del Pan a la calle Empedrada de suerte que todo el suelo de las dichas casas que cayere dentro de la plazuela echando un cordel desde las casas de ayuntamiento a la calle dicha quede para la villa..." (A.Col.T.,Caja 257, n. 33). Además se conservan otras escrituras de venta de casas en la misma plaza (A.Col.T., Caja 303, n. 81).

34 Manuel Hernández Lanchas: La crisis del Antiguo Régimen en el Santo Hospital de la Misericordia de Talavera de la Reina, 1789-1837. Toledo, 1991, pág. 33.

35 El 23 de mayo de 1593 el cabildo de la Colegiata de Santa María patrono del hospital, llegó a un acuerdo con el ayuntamiento para ensanchar la plaza, consistiendo en el derribo del hospital a cambio de recibir un nuevo solar para su reconstrucción (A.Col.T., Caja 270, n. 143). El 2 de junio de 1595 se vuelve a firmar otro contrato similar (A.Col.T., Caja 270, n. 145). Citado por Fernando Marias, op. cit., IV, pág. 220.

36 Anónimo: Historia de la noble e insigne villa de Talavera. Siglo xvII. Copia. Manuscrito B.N., sig. 1720 , fol. $20 \mathrm{v}$. 
Clemente (desaparecida), San Andrés, la plaza del convento de la Trinidad y la que había junto a las torres de San Benito (Calle Charcón) ${ }^{37}$. Curiosamente coinciden todas con plazas donde existía una iglesia o edificio religioso; se refuerza esa adecuación del espacio urbano a las necesidades de la fiesta religiosa dentro de la concepción de la ciudad como elemento simbólico-ritual.

Con todo, la dispersión de estos espacios abiertos aseguraba en cierta forma una red multinuclear de las funciones económicas y sociales de la villa. Con la apertura de estas plazas quedaba descentralizado el cuerpo central de Talavera, como único lugar de celebración de actos civiles o religioso-festivos.

Cuando el regimiento talaverano lleva a cabo la gestión del proceso repoblador de finales del siglo $\mathrm{xv}$ en algunos nuevos pueblos de la Jara (Pueblanueva, San Bartolomé de las Abiertas, por citar algunos) da una serie de normas que pueden considerarse como de índole urbanística, con cierta proyección para el futuro del lugar en cuestión. Así, se apuntan, por ejemplo, las siguientes condiciones para esta labor:

1. Que en medio de cada pueblo se haga iglesia, dejando junto a ella sitio para cementerio.

2. Que las calles salgan a la plaza e iglesia.

3. Que las casas que cada vecino ha de hacer sean de ocho tapias en lo largo y quince en lo ancho e que vayan derechas, etc. ${ }^{38}$.

Este código nos sitúa ante una concepción previa de planificación urbana, muy en conexión con nuevas mentalidades en función de la economía y las necesidades de los lugares y villas. En ese mismo código se apunta la anchura de las calles para el paso de carruajes, así como la prohibición de construir balcones o ventanas salientes que obstaculicen el paso.

La iglesia como elemento fundamental en la planificación urbana medieval aparece en estas normas como núcleo centralizador del trazado; los nuevos vecinos ocuparían terrenos edificables alrededor del templo parroquial, como era habitual en las ciudades de nueva planta que surgieron en la Castilla del siglo XI y XII ${ }^{39}$.

37 Cosme Gómez Tejada de los Reyes: Historia de Talavera. Antigua Elbora de los Carpetanos. Talavera, 1651. Manuscrito B.N. sig. 8.396, cap. 5.

38 A.M.T. Libro de Acuerdos 1500-1501, sesión de 17 de marzo de 1501. Esta nota la recoge don Clemente Palencia (Gabriel MORA DEL Pozo: Efemerides Toledanas, tomo I. Toledo, 1991, pág. 393).

39 Jean GaUTIER-DALCHE: «La ville hispanique au Moyen Age» en Concejos y ciudades en la Edad Media Hispánica. Madrid, 1990, pág. 16. 
Si bien esta serie de medidas pueden hacernos pensar en una nueva forma de administrar el suelo público y urbano, el proceso llevaría bastantes décadas en desarrollarse debido al choque de intereses que inevitablemente surgía. Mientras tanto las autoridades concejiles intentaban controlar las infracciones y abusos que se cometían en este campo.

En el municipio había siempre problemas de higiene y salubridad pública derivados de la acumulación de basuras, estiércol de los animales, formando los llamados muladares, término que se origina a partir de "muradal', precisamente por los depósitos que se almacenaban junto a los muros ${ }^{40}$. Pronto se apresuró el ayuntamiento a reconocer y remediar el daño que hacían estos vertederos incontrolados ${ }^{41}$. Ante el insistente ejercicio de los vecinos de acumular desperdicios por doquier, incluso en solares disponibles para la futura construcción de edificios, el regimiento tomaba medidas: «Que la calleja que está detrás de San Martyn de Antón Sánchez de Siguença pedie para fazer solar se çierre, porque de otra manera se fara alli muladar... ${ }^{42}$.

Otras transgresiones contra el espacio público las protagonizaban las zanjas y hoyos que se hacían sin permiso, obstaculizando el paso de viandantes y poniendo en peligro la seguridad vial. Así se refleja en un pregón del 3 de diciembre de 1505 en que se anunciaba que «ninguna persona sea osado de fazer foyo ni cavar en amas las plaçuelas de Santa María, donde se corren los toros, ni la dañen, so pena que por cada vez que fuere fallado que lo haze, que este ocho días en la carçel el que lo hiziere ${ }^{43}$. E igualmente cuando los residentes de alguna calle abrían una zanja: «Cometieron al señor corregidor que haga paresçer ante sy a çiertos vezinos que biven en la calle de los arrabales viejos, que son espeçialmente Juan Marqués e Juan de Cordova, e que sepan de un çanja que hazen en la dicha calle, y que provea como no se hagan hoyos en perjuiçio de la calle e de los vezinos que biven en ella" ${ }^{44}$.

40 SuÁfiez Alvarez, La villa de Talavera..., pág. 66.

41 Como se recoge en el acuerdo del 2 de diciembre de 1500 para que se visite y reconozca "el muladar de la Puerta de las Alcantarillas Viejas (que) están tan grande que haze daño en la çerca» (A.M.T. Libro de Acuerdos de 1500-150t, fol. 4 r.). O en el del 19 de agosto de 1502 que "mandaron a los almotaçenes que presentes estavan que luego limpien los muladares e las calles desta villa donde nuevamente estan fechos muladares e ay vasura echada» (A.M.T. Acuerdos 1501-1502, fol. 120 r.). Suarez Alvarez, op. cit., pág. 67.

42 A.M.T. Libro de Acuerdos 1521-1522, sesión 19 de febrero 1522.

43 A.M.T. Libro de Acuerdos 1505-1506. En esta misma sesion se mandó al alcalde que ufable con Alcala, el canonigo (de la Colegial) que faga adobar çiertos foyos que tienen fechos e dañada çierta parte de la plaçuela de Santa María”.

44 A.M.T, Libro de Acuerdos 1536-1537, sesión de 11 de octubre de 1536. 
Ante estas realidades de daño al espacio público de la villa se reglamentaba que los vecinos debían solicitar al ayuntamiento el permiso correspondiente cuando se proyectaba cualquier tipo de obra en la calle. Dentro de este capítulo se localizan varias intervenciones, desde el tapiado de muros que estaban arruinados y que amenazaban a las personas ${ }^{45}$ o el rebaje del nivel de la calle para el mejor tránsito de las aguas ${ }^{46}$.

Pero un asunto importante que ocupaba el capítulo de urbanismo del regimiento talaverano eran las rectificaciones que había que hacer en el entramado urbano para cambiar el aspecto de la villa. Entre las medidas que se pusieron en marcha, desde mediados del siglo xv, figuraba la necesidad de dejar espacios libres, sin edificar ${ }^{47}$, para airear y ensanchar calles angostas y tortuosas.

Debido a su trazado de ascendencia islámica, Talavera poseía a finales de la Edad Media un plano irregular, muy aproximado a la imagen que nos describe Torres Balbás de una ciudad islámica: «En las ciudades hispanomusulmanas había unas cuantas calles transversales o radiales, de trazado sinuoso, que enlazaban las entradas o puertas más concurridas del recinto murado, encauzando el tráfico a través de ellas. En caso de

45 El señor Francisco VÁZQUEZ, regidor, pedia licencia «para atapiar y çerrar una calleja questa a las espaldas de una casa que tiene çerca de la yglesia del seffor Sant Miguel desta dicha villa... porques mui angosta... y no sirve la dicha calle sino para fazer en ella muladar algunos vezinos que no tienen corrales» (A.M.T. Libro de Acuerdos 1530-1531, 14 de junio 1531). Y otra petición de Juan de Plasencia para que en sus casas, que tenia junto a la Puerta de la Miel entre un corral suyo y el muro desta villa esta una callejita de tres pasos de ancho e avra que quinze pies de largo, y los vezinos del barryo echan alli estiercol y otras viscosidades de quel dicho muro y las tapias estan caydas y los muchachos tienen logar de apedrealle las aves y le han hurtado otras cosas» por lo que solicitaba licencia para " que lo çierre e junte con el dicho corral» (A.M.T. Libro de Acuerdos 1523, sesion 21 de octubre).

46 A.M.T. Libro de Acuerdos 1523, sesicn 7 de agosto (presidida por el alcalde y bachiller Fernando DE RoJAS): «A petiçion de Martyn Rodríguez, obrero vezino deesta villa, los dichos señores le dieron liçençia para adobar un poco de la calle del Lagar de la Cera (para) para que corran las aguas a salir por la Puerta del Ryo syn perjudicar a los vezinos de la calle». También el acuerdo de 18 de julio de 1522 por el que se delegaba al procurador Fernando de la Rua para que supervise las obras que había de hacerse para "poder hechar fuera el agua de la charca y se faze cabe Sant Antón (junto a la Puerta de Cuartos)».

47 En sesión de 10 de mayo 1454 el concejo hizo merced al monasterio de Santa Catalina «del muladar que está çerca del dicho monasterio, en frente las casas de Juan Sánchez de Talavera, e con condizion que le tengan fecho plaça e non fagan en el edifiçio alguno" (SUÁREZ Álvarez, op. cit., pág. 62). El Padre Torrejón en su Libro de Antiguedades... (1596) escribe: «el año de mil y quatroçientos y sesenta y seis hiço donaçion el ayuntaamiento a esta casa de un solar que estava junto a la huerta desta casa que eran unas casillas de judios los quales pidieron los religiosos porque si las comprava alguna persona podía edificar allí. Esta última donación nos muestra claramente la gran influencia que tenían algunos poderes eclesiásticos en la administración civil. En este caso la orden de San Jerónimo a la que pertenecían los frailes del monasterio 
existir arrabales extramuros, solían prolongarse por éstos. De esas calles radiales arrancaban otras secundarias, angostas, que se quebraban y torcían a cada paso... con numerosos callejones ciegos, sin salida... e irregulares mayores ${ }^{48}$. Todo ello se deduce de los datos aportados por las fuentes documentales y el análisis de la evolución urbanística del plano de la ciudad. La existencia de adarves, callejones estrechos ("de tres pasos de ancho»), y otros sin salida, son elementos típicos de este período.

El ensanche, pues, de las calles era una exigencia que el regimiento aplicaba a los moradores, y procuraba velar para que no se cometieran abusos o apropiación indebida de suelo público. Por ejemplo en 1523 se quejaban unos vecinos porque una familia había construido un edificio y horno junto a un corral que estrechaban la calle visiblemente y perjudicaba su tránsito «porque la pared la faze más gruesa de lo quella era». El ayuntamiento acordaba que «den horden como la calle quede más ancha en haziendo su obra y questa villa se lo gratifique e pague.... ${ }^{49}$.

Para esta labor de policía y supervisión de la acciones en materia urbanística y de obras públicas o privadas, tenía el ayuntamiento unos oficiales incluidos en la nómina del concejo. En la segunda mitad del $\mathrm{xV}$, los llamados alarifes, eran dos en Talavera, uno cristiano y el otro mudéjar ${ }^{50}$. Este oficio estaba vinculado técnicamente a las labores de peritaje en materia de construcción e ingenieria ${ }^{51}$. A principios de la nueva centuria aparece la figura del "obrero de las obras de la villa» con atribuciones semejantes a las del anterior, si bien se ocupa de las escasas obras públicas que acomete por estos años iniciales el ayuntamiento talaverano. Éste dictamina al respecto del control de las obras que con el peritaje de los alarifes, se vaya respetando la nueva anchura de las calles ${ }^{52}$.

de Santa Catalina. Y sobre todo en materia de suelo urbano y su aprovechamiento, donde siempre surgían choques de intereses. Esta última nota del Padre Torrejón está corroborada por un documento con fecha de 17 de mayo de 1482 que se conserva en el A.H.N., sección Clero legajo 7.121, y que lo transcribe íntegro Pilar Leon Tello: Judíos de Toledo. Madrid, 1979, t.l, págs. 504-507.

48 L. TORRES BALBÁs: "La Edad Media» en Resumen histórico del urbanismo en España, pág. 79-80.

49 A.M.T. Libro de Acuerdos 1522-1523, sesión 3 julio 1523.

so SuÁrez Álvarez, op. cit ., pág. 220.

s1 Consuelo GómEZ LOPEZ: “Los Alarifes en los oficios de la construcción, siglos $X V-X V \mid »$. Espacio, Tiempo y Forma. Serie viı, tomo 4, págs. 40-41.

52 «Asy mesmo mandaron notificar a Lope Martínez e Juan de la fuente alarifes desta villa que quando se hiziere hedifficio en calle pública no lo hagan syn que notiffiquen a este ayuntamientos para se nombre persona con ellos que vean el anchura que an de quedar en la calle..." (A.M.T. Libro de Acuerdos 1540-41, sesión 8 de marzo 1541. 
La muralla suponía para el concejo un obstáculo para el desarrollo urbano y socioeconómico, una vez que parecía que su función militar no tenía ya mucho sentido. Desde los últimos conflictos bélicos con la ciudad de Toledo en tiempo de Juan II, en los que la villa tuvo que poner medios para la defensa de la misma ${ }^{53}$, no había necesidad de mantener tan costosas obras que menguaban las arcas del concejo.

Si bien desde el siglo XIII, con las normas preceptivas de las Partidas de Alfonso X, se había procurado dejar libres los muros, sin edificar casa o edificio alguno junto a ellos para mejor defensa de las ciudades, ya desde mediados del XV se habían construido casas adosadas a la muralla, y se habían suprimido muchos callejones o espacios entre el caserio y aquella. En ocasiones las mismas torres albarranas servían de asiento para residencia de algunos vecinos, como exponente claro de aprovechamiento del espacio; fundamentalmente serán las clases privilegiadas o personas con cargos oficiales las que accedan a este tipo de uso. Así por ejemplo, en sesión del ayuntamiento del 29 de abril de 1523 y «a petyçion del bachiller Fernando de Rojas, los dichos señores le hizieron mered del uso de una torre albarrana questá enfrente de su casa, para que la tenga limpya y byen tratada y çerrada..." ${ }^{54}$.

Se llegó incluso en el siglo XVI a derribar gran parte de la barbacana o antemural que rodeaba la primera cerca, uniendo entre sí las torres albarranas ${ }^{55}$ para el mejor servicio y paso del vecindario. Todavía en 1567 se mantenía, no obstante gran parte de esta barbacana en el lado occidental de la villa, lo que hoy se conoce como Entretorres, según se aprecia en la magnífica panorámica del holandés Wyngaerde ${ }^{56}$.

Entre las claras connotaciones de tipo demográfico hay que vislumbrar en estas actuaciones del concejo un posible signo de «modernidad», al deshacerse de vestigios que recordaban el pasado, como volverá a ocurrir con mayor virulencia durante el siglo XIX, en el caso de Talavera ${ }^{57}$.

53 SUÁREZ ÁLVAREZ recoge las disposiciones del ayuntamiento en materia de reparación y vigilancia de puertas y murallas reflejadas en los libros de acuerdos de 1450-59. La villa de Talavera..., págs. 43-48.

54 Inés VALVERDE AZULA: «Documentos referentes a Fernando de Rojas en el Archivo Municipal de Talavera de la Reina». Celestinesca, vol . 16, núm. 2 ( 1992 ), pág. 100.

55 Conde de Cedillo: Catálogo Monumental de la Provincia de Toledo. Toledo, 1959, pág. 336. CésAR PACHECo Jiménez: “Notas acerca de las torres albarranas de Talavera (II)». Carpeta de las Artes, 2 (1993).

56 R.L. KaGaN: Ciudades del Siglo de Oro. Las vistas españolas de Van den Wyngaerd. Madrid, 1986, págs. 347-348.

57 Jacques LE GoFF en su artículo «Construcción y destrucción de la ciudad amurallada. Una aproximación a la refiexión y a la investigación" (en La ciudad y las murallas, Madrid, 1991, págs. 1120) apunta algunas de las motivaciones de destrucción de las murallas en las ciudades en expansión. 
De nuevo asistimos a una nueva intervención para la transformación del espacio urbano, entendido éste como lo define Ricardo Izquierdo «espacio abierto» fundamentalmente referido al trazado viario ${ }^{58}$.

Relacionada con la intervención en el muro estaba la erección de nuevas puertas. Ésta debía responder a una necesidad no sólo urbanística sino a veces fiscal. A fines del medievo se abrió la llamada Puerta Nueva o de las Cebollas que algunos autores la suponen edificada en 1579. Sin embargo, y siguiendo a la doctora Suárez Álvarez está demostrada su existencia en el siglo XV, pues ya se cita en los libros de acuerdos de 1450 59. Debemos suponerla pues obra de principios de esa centuria o finales del $x V, y$ en todo caso atribuirla una reconstrucción en 1579. Con esta puerta quedaban comunicadas dos zonas estratégicas de la villa: la plaza de la Corredera, o lo que hoy se denomina plaza del Mercado o del Palenque, y la Plaza del Pan. Fue derribada junto con un fragmento de muralla cuando los padres jesuitas construyeron el convento e iglesia del Palenque, a finales del xvil.

Otra realización en este sentido es la apertura de la Puerta de Sevilla, la única que se conserva en Talavera. Se levantó en el segundo recinto amurallado en 1579 por mandato del cardenal Quiroga, señor de la villa, cuyas armas aún se mantienen encima del arco. Ubicada en la calle de las Carnicerías, este nuevo acceso suponía una reestructuración del espacio funcional. Permitía controlar las mercancías que llegaban del otro lado del río para venderse en su mercado. De ahí que el regimiento posiblemente, pensara en abrir un vano en la muralla del arrabal nuevo y habilitar una calle - la de Sevilla - que discurría paralela a los muros del Alcázar, para comunicar con la calle donde se ubicaba el edificio de las carnicerías y después con la plaza pública. Con esto se evitaban además los problemas de tráfico de carretas y animales, que entraban desde el puente viejo por la Puerta del Río, y tenían que atravesar todo el centro de la "villa" para salir por el Arco de San Pedro a la misma plaza del mercado.

En estas mismas décadas del siglo se debió abrir la pequeña puerta de Rodrigo Niño en el segundo muro, ubicada en la calle que aún lleva el nombre de Postiguillo. Comunicaba la parte norte del arrabal mayor con la urbanizada Cañada de los Alfares. Se hacía imprescindible habilitar este paso para mayor comodidad de los vecinos del llamado Barrio Nuevo. La

\footnotetext{
58 Ricardo IzouIERdo Benito: «El espacio público de Toledo en siglo Xv». Toletum, 26 (1991), pág. 28.

59 SuÁRez Álvarez, op. cit., pág. 39, nota 18.
} 
iniciativa privada parece ser que en esta ocasión hizo posible esta intervención urbanística ${ }^{60}$.

Otra puerta o postigo que se abrió en esta etapa fue la llamada de las Pescaderías. En este caso fue a petición del convento de San Francisco, que solicitaba al ayuntamiento «manden abrir un postigo en el muro que esta enfrente de Santa Leocadia ${ }^{61}$ por la nesçesidad que tienen los becinos que biven dentro de la billa y para yr al dicho monesterio las mugeres no pueden yr sino por la plaça..." ${ }^{62}$. Visto los pro y los contras y asegurado el regimiento de los vecinos que podían contribuir a los gastos de la obra, en otra sesión decidieron «dar lizenzia al padre guardian y convento de San Francisco para que hagan abrir una puerta... junto a la torre del alcaçar ${ }^{63}$ y la hagan con su arco y puertas y que se haga a costa de los dichos flayres o de quien les ayudare..." ${ }^{64}$. Nuevamente asistimos a una transformación del espacio público gestionada por lo privado aún con supervisión del municipio.

Con todas estas medidas el aspecto de la villa iba cambiando y sus recursos urbanísticos se iban ampliando. De tal manera que se consolida en este siglo un sentido de lo urbano que posiblemente no se había dado anteriormente. Cuando García Fernández nos describe Talavera hacia 1560 con esa serie de elementos un tanto idealizados se está aproximando a un proyecto de ciudad moderna ideal, muy acorde con la mentalidad clasicista del quinientos español: «...antiguamente fue lugar más enfermo por la humedad del, de presente no es tanto por en unos años se an hecho la maior parte de los buenos hediffiçios que en ella parescen y por las buenas y nuevas labores que en las casas se an hecho y por averse empedrado las calles» ${ }^{65}$.

${ }^{60}$ El nombre de Rodrigo Niño lo tomó de uno de los vecinos que vivía en sus proximidades y presumiblemente fue el que llevó a cabo la obra del postigo. Su nombre está documentado en 1563: "Leyose petiçion de RoDRIGo Niño que pidee en nombre del y de los vezinos que biven en su calle que por quanto la calle que va al meson nuevo esta desenpedrada y se haze mucho lodo en tiempo de ynvierno por ser angosta la manden sus mercedes empedrar" (A.M.T. Libro de Acuerdos 1563, sesión 15 de octubre).

${ }^{61}$ Esta parroquia ocupaba el solar comprendido entre la calle de Carnicerías y el callejón de la Caridad.

62 A.M.T. Libro de Acuerdos 1559-60.

${ }_{63}$ Justamente en la actual calle de Pescaderías y junto a la torre albarrana del antiguo alcázar.

6 4 Libro de Acuerdos 1559-60, s/f. Lo citamos en César PACHECO: Las antiguas puertas de Talavera. Inedito.

55 Garcia Fernández: Historia de la villa de Talavera. Talavera, 1560? Manuscrito B.N. sig. 1722, pág. 3. 
Precisamente el empedrado de muchas calles de la villa tiene lugar en la primera mitad de dicha centuria, aunque se deduce por la documentación que en los años finales del $x v$ ya se debieron empedrar algunas otras. Más arriba señalamos la particularidad de la calle como elemento del paisaje urbano prioritario, susceptible de las mutaciones y acondicionamientos efectuados en esta etapa. Al ser los espacios principales de tránsito en toda ciudad, la afluencia de personas y vehículos acababan degradando su firme. De ahí que con nuevas perspectivas de urbanidad el concejo de Talavera, como el de tantas villas y urbes, se planteara el problema de la pavimentación. Quizá sea este capítulo el que adquiere para nosotros más alta consideración por ser objeto de un análisis más pormenorizado.

Para el vecino Toledo también se puede hablar de una preocupación por la pavimentación de sus calles ya en los años finales del XV. Curiosamente se da el mismo proceder tanto en la imperial ciudad como en Talavera a la hora de afrontar el problema de los empedrados y su financiación ${ }^{66}$. Ya en 1497, el regimiento, las justicias y el concejo de Toledo pedían a los Reyes Católicos licencia para echar la «sisa» ${ }^{67}$ y poder así costear los gastos que las obras conllevarían. Los monarcas contestaban que primero se hiciese relación de aquellas calles que más necesidad tenían de pavimentarse y el monto a que podían ascender ${ }^{68}$.

Por su parte, Talavera hacía lo mismo en fecha posterior. Primeramente consultó con el señor de la villa, el arzobispo de Toledo, el entonces cardenal Cisneros, para pedir la licencia oportuna para el empedrado de varias calles. Tras las oportunas gestiones recibía el ayuntamiento talaverano un mandamiento del arzobispo en el que se señalaban las causas mismas de la necesidad de la obra: «nos fue fecha relaçion que queres fazer enpedrar esa nuestra villa porque con las humedades es muy enferma, e sy se enpedrara redundaria en mucha utilidad e salud al pueblo, e que para lo fazer erya bien se cargase alguna sysa en la carne e pescado... e nos suplicastes que para ello vos diesemos liçençia e facultad... mandamos dar la presente por el tenor de la qual vos damos e conçedemos la dicha liçençia (para) para echar la dicha sysa en las cosas e cantiydad que paresciere, por dos años primeros syguientes que corran

56 Eloy Benito RuANO: «El antiguo empedrado de las calles de Toledo» en Homenaje a Fernando Jiménez de Gregorio. Toledo, 1988, págs. 143-146.

${ }^{67}$ Impuesto indirecto que solía aplicarse a los productos básicos de mantenimiento, sobre todo la carne y el pescado, en su transacción comercial, por un período de tiempo determinado.

68 Dada esta carta en Valladolid a 28 de septiembre de 1497: A.M. Toledo, Cajón 4, Legajo 1, núm. 1. Lo cita aparte de Benito Ruano, pág. 143, Ricardo Izquierdo, «El espacio público de Toledo...", págs. 62-63. 
desde el día que este mandamyento les fuere presentado a los quales segund e en la manera que dicha es..." ${ }^{69}$. A pesar de la premura que existía para aplicar la sisa no fue hasta el mes de septiembre cuando se decide poner en marcha la subida del precio de los pescados, de la vaca y el carnero en 1 maravedís ${ }^{70}$.

Igualmente en carta de don Fernando y doña isabel, fechada en Alcalá de Henares el 27 de junio de 1503 (ver apéndice documental) se mandaba: «...que luego que con esta nuestra carta fuerdes requeridos, tomeis maestros canteros que sepan de los susodicho e ayais ynformacion çerca dello e sepays como e de que manera ha pasado e pasa, e que tanto es lo que queda por enpedrar de la dicha villa...y que costara, y si ay en la dicha villa de los propios con que lo puedan façer.... ${ }^{71}$.

En el caso de Toledo, parece ser que no se llegó a «echar la sisa» por no estimarse procedente, después de la previa consulta a la autoridad real, y se opto por la vía del repartimiento ${ }^{72}$. Sin embargo en Talavera posiblemente y tras las gestiones realizadas por el municipio no tenía otro remedio. Sólo hay que tener en cuenta el saldo negativo que arrastraban los propios de la villa - unos 50.000 maravedis en el período septiembre de 1500 al mismo mes de $1501-{ }^{73}$ para comprender las frecuentes imposiciones de tributos extraordinarios a los que estaba obligado el regimiento. Con ellos podía hacer frente, al menos en parte, a gastos excepcionales, entre ellos el empedrado de calles. Mediante las derramas o repartimientos unas veces, que sólo podían afectar a los propietarios de las casas alineadas en torno a las calles empedradas ${ }^{74}$.

En ocasiones posteriores se volvió a poner en marcha el recurso de la sisa, como ocurrió en 1505 cuando el regimiento pide de nuevo la licencia al rey o al arzobispo, amparándose de nuevo en lo beneficioso que sería para la salud de la población «empedrar las calles ...como está

69 Este mandamiento está inserto en la sesión del 23 de marzo de 1502 (A.M.T. Libro de Acuerdos 1501-1502). Está fechada la carta del arzobispo en Alcalá el 24 de enero del mismo año.

70 Según el acuerdo del 16 de septiembre de 1502 se establecía que a partir del 29, día de San Miguel, "se echa un maravedí de sisa en cada libra de pescado e sardinas e truchas? que se vendieren en la dicha pescadería este presente año que se cumplirá por día de carnestolendas primero que viene del año venydero de... myll quinientos e tres años». Igualmente, el 28 se mandaba subir un maravedí más el precio de cada res de carnero, por ser insuficiente la sisa de la vaca únicamente. Todo ello "para la empedradura de las calles» (A.M.T. Libro de Acuerdos 1501-1502).

A.M.T. Obras Públicas. Calles 1503-1900, núm. 1.

Benito Ruano, op. cit., pág. 144.

SUÁREZ Álvarez, op. cit., pág. 239.

A.M.T. Libro de Acuerdos 1501-1502, fol 64 r. 
comenzado fazer, e para ello por ques obra de mucho gasto, sería necesario echar sysa...» ${ }^{75}$.

No obstante, está comprobado documentalmente cómo a la hora de afrontar las obras de pavimentación de las diversas calles durante todo el siglo XVI, se establece un sistema compartido en el que el municipio sufraga una tercera parte de los gastos y las dos restantes debían pagarlas los propietarios de las casas o inmuebles del tramo de calle empedrada ${ }^{76}$. En estas operaciones parece ser que no estuvieron exentos los clérigos, pues el acuerdo solía beneficiar también a la iglesia local, como ocurría en Toledo en el concierto entre el cabildo de la Catedral y el Ayuntamiento.

En cuanto a los precios marcados entre la villa y los empedradores profesionales parece ser que hubo desacuerdos en principio, si bien se estableció en unos 45 maravedís la tapia ${ }^{77}$, en torno a 1502. En este año, antes de realizar la operación de la sisa, una de las primeras calles que se empedró fue la de Zamora, actualmente calle de Mesones. Los vecinos de la misma manifestaban al ayuntamiento su malestar, ya que ellos tenían que empedrar a su costa la calle, y se les había asignado dos empedradores forasteros, Juan y Andrés de Valladolid ${ }^{78}$; éstos tasaban la obra en 45 maravedís la tapia, mientras que los moradores de la calle aseguraban que había "vezinos desta villa que lo toman e se encargan de la empedradura a quarenta maravedises por cada tapia, mayores que las tapias que agora hasen enpedrars ${ }^{79}$. Esto llevó a revisar el precio estipulado por los vallisoletanos, que al final pudieron concertar con los vecinos en la cantidad de 40 mrs. mediante obligación hecha ante el regimiento el 20 de enero de 1502.

75 A.M.T. Libro de Acuerdos 1504-1504, sesión 14 de febrero.

76 Así lo reflejan los libros de acuerdos municipales: «...que se pague conforme a las otras calies, que es el terçio la villa e lo demás los vezinos, cada uno lo que copiere en su parte e no mas..." (A.M.T. Acuerdos 1519, sesión de 3 de junio). O en otro acuerdo donde se dice "e que la villa pague una terçia parte, e los vezinos las dos partes... (sesión de 17 de diciembre de 1522).

${ }_{77}$ La tapia como medida de superficie era muy utilizada en esta epoca. Venía a equivaler a unos 14 metros cuadrados aproximadamente. Precisamente en uno de los acuerdos del regimiento aparecen especificadas estas dimensiones, si bien solian usarse diferentes tipos de tapias: "la tapia de a diez pies en largo e a çinco pies en ancho" (A.M.T. Libro de Acuerdos de 1502, sesión de 20 de enero); con esas medidas y torriando como longitud media del pie unos $28 \mathrm{~cm}$. nos resulta una cifra de 50 pies cuadrados que vienen a ser esos $14 \mathrm{~m}$. Sin embargo, cuando se quejaban los vecinos de la calle de Zamora a la hora de concertar con los empedradores el precio apuntaban que éstos tenían por costumbre hacer la tapia de «a ocho pies en largo e de quatro en ancho".

${ }_{78}$ A estos dos empedradores, los primeros documentados como tal en los libros de acuerdos, la villa les busca un alojamiento en un mesón según se refleja en la sesión del 14 de enero de 1502. Citado por Suárez Alvarez, pág. 63.

79 A.M.T. Libro de Acuerdos 1501-1502, sesión de 19 de enero. 
Lógicamente surgieron muchos problemas en la financiación de este tipo de obras; muchos vecinos se negaban a pagar o se demoraban eternamente originando las protestas de sus convecinos y de las autoridades locales. $Y$ no sólo las clases populares tenían este problema pues hasta el clero no quedaba exento. Por ejemplo, en fechas tardías como 1578 el empedrador Alonso Ruiz se quejaba de algunos vecinos que no le querían pagar la obra de la Cañada y apuntaba que entre ellos había «dos clérigos ques Alonso de Çorita y el benefiçiado Vargas que dizen que no le an de pagar» ${ }^{80}$.

Unas veces algunos vecinos pedían al ayuntamiento que les abonaran la parte correspondiente, un tercio de los gastos, a costa de los propios de la villa ${ }^{81}$, por haber corrido con los gastos de la empedradura. Pero otras veces tenían que ser los regidores los que obligaran a ciertos vecinos a pagar su parte correspondiente ${ }^{82}$.

El inicio de los empedrados de una calle venía dispuesto en ocasiones por los particulares de la misma, ante la utilidad y necesidad que veían en ello ${ }^{83}$. Puede decirse que en las tres primeras decadas del XVI, Talavera empedró gran parte de sus calles, (ver apéndice documental), si bien debió de reparar muchas de ellas a los pocos años por defectos de obra ${ }^{84}$.

80 A.M.T. Libro de Acuerdos 1577-78, sesión de 21 de mayo.

81 A.M.T. Libro de Acuerdos 1523, sesión de 28 de agosto: «Juan Lagarto pidió que le manden librar el terçio de la empedradura de su calle porque así está asentado en ello».

${ }^{82}$ Se dan numerosos casos de este tipo. Algunos recogidos por nosotros de los libros de acuerdos. Un caso singular es el del mercader de la Corredera Andrés Alvarez, que aparece repetidamente en las sesiones del regimiento de 1523 y 1524. La polémica surgía de la negativa de éste a empedrar una parte importante de esta calle principal del centro de la villa, dejando las obras a medias, pues ya se había comenzado la obra meses antes. Así, un vecino de la calle se quejaba ante las autoridades y pedía que se le obligue a terminar el empedrado, pues el mismo le había dado dos ducados de ayuda y el dicho Andrés «ha çesado la obra y no la faze segund que esta obligado, y que si asy oviese de quedar la obra que no se acaba, seria muy dañoso a todos los vecinos desta villa, y por estar la tierra movida, avria mayores lodos". Los regidores dictaminaron que se avise seriamente a Andrés Alvarez y que «dentro de tres dias comiençe aa fazer la obra, y no alçe la mano della fasta que la acabe" (A.M.T. Libro de Acuerdos 1523-1524, sesión de 21 de octubre). De nuevo insistía el mismo vecino en febrero de 1524, ante la negativa de Andrés.

23 “Juan de Talavera, escrivano, e Garçia de la Higuera, por sy e en nombre de elos otros vezynos de la calle de sus casas e de los vezinos de la calle que va desde la Çapateria a Barrionuevo, e dixeron que por que es utilidad e provecho de la villa, que les enepdren las dichas dos calles y sus merçedes las manden enpedrar" (A.M.T. Libro de Acuerdos 1511, sesión de 12 de febrero). Ver también nota 60.

${ }_{34}$ El caso de la Corredera referido es notorio, pues en 1531 (Libro de Acuerdos 1530-31, sesión de 15 de septiembre) los regidores y justicia trataban «del enpedrado de la Corredera, que se desfaze por estar mal hecho, para lo tornar a enpedrar...". En esta misma sesión, a petición de dos vezinos de la calle de Santa Leocadia "ques debaxo de las carniçerias mayores desta villa" mandaron volver a empedrarla porque según decian aquéllos « se faze un gran hoyo aunquesta empedrada, a cabo de lo qual todo el año esta mucho lodo hediondo en ella y es calle muy principal»" 
También se ocupó el ayuntamiento de procurar el empedrado de lugares de uso público que no eran estrictamente espacio viario. Así en 1527 se notificó al mesonero Francisco Segovia «que dentro de un mes primero siguiente faga linpiar e limpie el corral del concejo de esta villa e le faga alçar y enpedrar bien corriente que salga el agua del" ${ }^{85}$.

En el aspecto técnico, hay que subrayar que las obras de pavimentación en Talavera respondían a un modelo muy utilizado en otras ciudades o villas. El recurso del empedrado era una solución para terminar o al menos disminuir la suciedad de las calles y evitar la formación de lodozales. En Toledo se decidió que se hicieran las «madres» y los "cannos", es decir un sistema por el que las aguas podrían salir de las distintas viviendas y recogerse en las alcantarillas que corrían por el centro de las calles principales ${ }^{86}$. Las ordenanzas toledanas eran muy claras en este sentido para evitar que se deteriorase el sistema de aguas residuales. En esta ciudad en principio se había pensado pavimentar las calles con ladrillo, pero ante la oposición del cabildo de la Catedral se optó por el empedramiento que resolvía por muchos años el problema ${ }^{87}$.

En Talavera debieron regir las misma razones, pues el ladrillo utilizado en pavimentos solía utilizarse más bien para cierto tipo de viviendas que podían permitirse esos gastos, y en pocas ocasiones se empleaba en espacios abiertos o de uso público. En cambio, el canto rodado resultaba un material mucho más barato, debido a las inmensas graveras que existen en las orillas del propio Tajo y arroyos circundantes de Talavera. Su perdurabilidad era además indiscutible por encima del ladrillo, más resistente al agua y a la erosión.

El canto de río estaba presente en las construcciones talaveranas desde época musulmana, formando parte de la mampostería de la muralla, por ejemplo, con lo cual era un material con bastante tradición en Talavera.

Estas actuaciones de pavimentación supusieron, pues, uno de los elementos de transformación del espacio urbano más relevantes de este período. Los cambios realizados en el aspecto de la villa pronto se hicieron

as A.M.T. Libro de Acuerdos de 1527, sesión 15 febrero.

so Ricardo IzQUiERDO, op. cit., pág. 46.

87 Juan García Oro: La Iglesia de Toledo en tiempo del Cardenal Cisneros (1495-1517). Toledo, 1992, pág. 220. También lo recoge el acuerdo Eloy Benito, El antiguo empedrado de las calles de Toledo, pág. 144 : "Que la dicha çibdad no se ladrillase, porque segund el ladrillo de dicha çibdad non era bueno, duraria muy poco". 
notorios, a juzgar por la imagen que nos presenta García Fernández en su «Historia de Talavera» (1560) ya referida: «...en unos años se an hecho la maior parte de los buenos hedeffiçios que en ella paresçen y por las buenas labores que en las casas se an hecho y por averse empedrado las calles...», o en la vista panorámica del holandés Wyngaerden (1567), donde aparece Talavera como una gran villa, fortificada y con un alto índice de edificios de buena factura; en definitiva un buen ejemplo de urbe transformada en los cruciales años de un cambio de época y de mentalidad.

\section{ANEXO I}

1503, 27 de junio. Alcalá de Henares

Carta de los Reyes Católicos pidiendo a las justicias y regimiento de la villa de Talavera más información para poder otorgar el permiso y licencia para echar la sisa en los artículos de mantenimientos, y dedicarlo al empedrado de algunas de sus calles.

\section{A.M.T.Obras públicas. Calles 1503-1900}

«Don Fernando e doña Ysabel, por la graçia de Dios rey e reyna de Castilla, de León, de Aragón, de Seçilia, de Granada, de Toledo, de Valençia, de Galizia, de Mallorcas, de Sevylla, de Cerdeña, de Córdova, de Córçega, de Murçia, de lahén, de los Algarves, de Algezira, de Gibraltar e de las yslas de Canaria, condes de Barçelona e señores de Vizcaya e de Molina, duques de Athenas e de Neopatria, condes de Rosellon e de Cerdanya, marqueses de Oristán e de Goçiano, a vos, el alcalde mayor e otras justiçias de la villa de Talavera, salud e graçia. Sepades que por parte del conçejo, justiçia, regidores, ofiçiales e omnes buenos desa dicha villa, nos fue fecha relaçion por su petiçion diziendo que la dicha villa está poblada en lugar muy úmido, e por que la prinçipal cabsa de la dicha umidad es por que toda el agua que llueve se consume en las calles, diz que acordaron de enpedrar las dichas calles para remediar los suso dicho, e que para ello se echasen por sysa algunas contyas de maravedises en los mantenimyentos que en la dicha villa se vendiesen, en la qual sysa contribuyesen los dichos clérigos juntamente con los otros vesynos de la dicha villa, e desta manera diz que se ha enpedrado mucha parte de la dicha villa, e otra parte della diz que queda por se enpedrar e que no tyenen de que lo cumplir e façer, e nos fue 
suplicado e pedido por merçed les mandásemos dar liçençia e facultad para que pudieden echar las dichas calles en los matenymientos de carne y pescado que en la dicha villa se vendiesen, o que sobre ello proveyésemos como la nuestra merçed fuese; lo qual visto en el nuestro consejo, fue acordado que devíamos mandar dar esta nuestra carta en la dicha razón, e nos tovímoslo por bien, porque vos mandamos que luego que con esta nuestra carta fuerdes requeridos, toméis con vos maestros canteros que sepan de los susodicho e ayáis ynformaçion çercaa dello e sepáys cómo e de qué manera ha pasado e pasa, e que tanto es lo que queda por enpedrar de la dicha villa, e sy ay nesçesidad de se enpedrar y que costará, y si ay en la dicha villa de los propios con que lo puedan façer e donde e como se podría aver lo que asy costase con menos daño e perjuizio de los vezinos e moradores della e de todo lo otro que vos vierdes que es nesçesario aver ynformaçion, e la dicha ynformaçion avida e la verdad sabida es puesta en linpio e sygnada de escrivano ante quien pasare e firmada de vuestro nombre e çerrada e sellada en pública forma en manera que haga fe la enbyad ante nos el nuestro consejo para que en el se vea e se provea como fuere justiçia, e non fagades ende al so pena de la nuestra merçed e de diez myll maravedises para la nuestra Cámara. Dada en la villa de Alcalá de Henares, a veynte y siete dias del mes de junyo, año del nasçimiento de nuestro Señor lhesuchristo de myll e quinyentos e tres años.

(Fiımas) llegible (Rúbrica); Perus, doctor (Rúbrica); Licenciatus, registrata (Rúbrica); Licenciatus de Cifuentes (Rúbrica); Licenciatus de Carvajal (Rúbrica); Licenciatus Santiago (Rúbrica).

Yo, Iohan Ramires, escrivano de Cámara del Rey e de la Reyna, mis señores, la fize escrivir por su mandado con acuerdo de los del su consejo.

Las Justiçias de Talavera ayan ynformación que cuanto queda por enpedrar de las calles della e que contyas de maravedises serán menester para ello e sy la villa tyene propios se puedan aver los maravedises que fueren menester para acabar de lo enpedrar e de qué manera se podrá aver con el menos daño de la villa y la enbien (Rúbrica).»

\section{ANEXO //}

Relación de calles empedradas en el primer tercio del siglo xvi en Talavera. 
La transformación del espacio urbano de Talavera de la Reina en el siglo xvı

\begin{tabular}{llrc}
\hline CALLE & NOMBRE ACTUAL & No PLANO & AÑo \\
\hline ALMAYZO & Alamillo & 2 & 1533 \\
BAÑO & Baño & 6 & 1502 \\
Bajo Carnicerías & Antigua Calle Sevilla & 17 & 1518 \\
CORREDERA & Corredera del Cristo & 4 & $1523-24-31$ \\
BARRIONUEVO & Barrionuevo & 3 & 1506 \\
EMPEDRADA & Gabriel Alonso de Herrera & 11 & 1506 \\
García de la HIGUERA & Ramón y Cajal & 7 & 1502 \\
Juan LAGARTO & $?$ & - & 1516 \\
MESONES & Mesones & 1 & 1501 \\
Puerta de NAZAR & + & $L$ & $1519 / 33$ \\
Puerta NUEVA & Palenque & LL & 1518 \\
Del y Puerta del RIO & Río y C/ Puerta del Río & 8 & $1511-18-22$ \\
& & & $1523-31$ \\
SAN BENITO & Herrerías y San Benito & 12 & 1519 \\
SAN CLEMENTE & San Clemente & 13 & 1533 \\
SAN GINES & San Ginés & 14 & 1526 \\
SAN PEDRO & Pza. San Pedro & 21 & 1519 \\
SANTA LEOCADIA & Pza. y C/ Santa Leocadia & 15 & 1531 \\
SANTA LUCIA & Santa Lucía & 16 & 1533 \\
SOL & Sol & 10 & 1531 \\
ZAMORA & Mesones & 1 & 1502 \\
ZAPATERIA A BARRIONUEVO & Entrada a Barrionuevo & 18 & 1511 \\
\hline
\end{tabular}

(Fuente: A.M.T. Libros de Acuerdos)

\section{CALLES}

- 1. Calle de Zamora y Mesones.

2. Calle del Almayzo.

3. Calle de Barrionuevo.

4. Calle de La Corredera.

5. Calle Real.

6. Calle del Baño.

7. Calle de García de la Higuera.

8. Calle del Río.

9. Calle de las Carnicerías.

10. Calle del Sol.

11. Calle Empedrada.

12. Calle de San Benito.

13. Calle de San Clemente. 
14. Calle de San Ginés.

15. Calle y plaza de Santa Leocadia.

16. Calle de Santa Lucía.

17. Calle «bajo Carnicerías» (Sevilla).

18. Calle de «Zapatería de Barrionuevo».

19. Calle de Zapaterías.

20. Calle «tras la cárcel de la Corona».

21. Plaza de San Pedro.

\section{PUERTAS Y POSTIGOS}

- A. Puerta de Cuartos.

B. Puerta de Mérida.

B'. Puerta de la Miel.

C. Puerta de las Alcantarillas Viejas.

D. Postigo de Vengamedel.

E. Puerta de las Alcantarillas Nuevas.

F. Puerta de Zamora.

G. Postigo de Rodrigo Niño.

H. Puerta de Toledo.

!. Puerta del Sol.

J. Puerta de Sevilla.

K. Postigo del Alcázar o de las Pescaderías.

L. Postigo de Nazar.

LL. Puerta Nueva.

M. Puerta de San Pedro.

N. Puerta del Río.

PLAZAS

a. Plaza del Pan o de Santa María.

b. Plaza Pública.

c. Plaza de Santiago.

d. Plaza de San Miguel.

e. Plaza de San Benito.

f. Plaza de San Andrés.

g. Plaza de la Trinidad.

h. Plaza del Salvador. 